\title{
RESEARCH
}

Open Access

\section{Utilization of deworming medication and its associated factors among pregnant married women in 26 sub-Saharan African countries: a multi-country analysis}

Betregiorgis Zegeye ${ }^{1}$, Mpho Keetile², Bright Opoku Ahinkorah³ ${ }^{3}$ Edward Kwabena Ameyaw³, Abdul-Aziz Seidu ${ }^{4,5}$ and Sanni Yaya ${ }^{6,7^{*}}$ (iD

Abstract: Background: Deworming is one of the strategies to reduce the burden of anemia among pregnant women. Globally, pregnant women in sub-Saharan Africa are more affected by anemia. Therefore, this study examined both the coverage and demographic, socioeconomic, and women empowerment-related factors associated with the utilization of deworming medication among pregnant married women in sub-Saharan Africa.

Methods: We used data from the most recent Demographic and Health Surveys of 26 countries in sub-Saharan Africa conducted between 2010 and 2019. Using Stata version-14 software, analysis was done on 168,910 pregnant married women. Bivariate and multivariable logistic regression analyses were conducted to examine the factors associated with the utilization of deworming medication. The results were presented using adjusted odds ratios (aORs) at 95\% confidence intervals (Cls).

Results: The pooled results showed that about 50.7\% (95\% Cl 48.2-53.3\%) of pregnant married women in the studied countries took deworming medications, and this varied from as high as $84.1 \%$ in Sierra Leone to as low as $2 \%$ in Angola. Regarding sub-regional coverage, the highest and lowest coverages were seen in East Africa (67.6\%, 95\% Cl 66.0-69.1\%) and West Africa (24.3\%, 95\% Cl 22.4-26.4\%) respectively. We found higher odds of utilization of deworming medication among older pregnant married women $(\mathrm{aOR}=1.93,95 \% \mathrm{Cl} 1.32-2.84)$, women with educated husbands ( $\mathrm{aOR}=1.40,95 \% \mathrm{Cl} 1.11-1.77$ ), wealthier women ( $\mathrm{aOR}=3.12,95 \% \mathrm{Cl} 1.95-4.99$ ), women exposed to media (aOR=1.46, 95\% Cl 1.18-1.80), and those who had four or more antenatal care visits (aOR=1.51,95\% Cl 1.24-1.83).

\footnotetext{
* Correspondence: sanni.yaya@uOttawa.ca

${ }^{6}$ School of International Development and Global Studies, Faculty of Social Sciences, University of Ottawa, 120 University Private, Ottawa, ON K1N 6N5, Canada

${ }^{7}$ The George Institute for Global Health, Imperial College London, London, UK

Full list of author information is available at the end of the article
}

(c) The Author(s). 2021 Open Access This article is licensed under a Creative Commons Attribution 4.0 International License, which permits use, sharing, adaptation, distribution and reproduction in any medium or format, as long as you give appropriate credit to the original author(s) and the source, provide a link to the Creative Commons licence, and indicate if changes were made. The images or other third party material in this article are included in the article's Creative Commons licence, unless indicated otherwise in a credit line to the material. If material is not included in the article's Creative Commons licence and your intended use is not permitted by statutory regulation or exceeds the permitted use, you will need to obtain permission directly from the copyright holder. To view a copy of this licence, visit http://creativecommons.org/licenses/by/4.0/. 
Conclusions: Enhancing women's education, disseminating information about maternal healthcare services through mass media, and ensuring that women from economically disadvantaged households benefit from national economic growth can be considered as deworming medication improvement strategies in sub-Saharan Africa. Moreover, providing more attention to adolescents or young pregnant women and increasing the number of antenatal care visits could be considered to increase deworming uptake among pregnant married women.

Keywords: Deworming, DHS, Factors, Global health, Pregnant women, Sub-Saharan Africa, Utilization

\section{Background}

Soil-transmitted helminths (STH) is one of the major public health problems worldwide [1-6]. Globally, approximately 1.5 billion people are affected by STH [6]. Majority of women of reproductive age (WRA) including pregnant women are the most affected $[3,4,6]$. Most of the disease burden occurs in the tropical and subtropical areas of sub-Saharan Africa (SSA) and South East Asia [5]. WRA in South East Asian and African regions are responsible for $74.7 \%$ of all STH risk among WRA [3, 4]. Hookworm and whipworm (Trichuris trichiura) are the most common helminths among pregnant women $[2,4,6]$. Pregnant women especially are at particular risk for STH $[6,7]$. Pregnant women with intestinal parasitic infection are at increased risk of maternal complications and adverse perinatal outcomes such as anemia, low birth weight, and perinatal mortality [8, 9]. Anemia affects approximately $39 \%$ of WRA, including pregnant women in SSA [10], which is higher than the average in low- and middle-income countries (LMICs) (35.4\%) and worldwide (33\%). The prevalence of anemia among pregnant women in SSA is $46 \%$ [11].

The World Health Organization (WHO) recommended deworming or preventive chemotherapy for pregnant women after the first trimester, using a single dose of mebendazole (500 mg) or albendazole (400 mg) in areas where there is $40 \%$ or higher anemia prevalence among pregnant women and the prevalence of $T$. Trichiura and hookworm is $20 \%$ and above $[6,12,13]$. As documented in several prior studies, prevention chemotherapy or deworming of pregnant women and children significantly enhances hemoglobin level and nutritional status [14-16]. Women who are dewormed during pregnancy tend to have an improved birth weight $[17,18]$ and a reduction in prevalence of low birth weight [19].

In 2001, representatives at the World Health Assembly universally recognized a determination (WHA54.19) urging endemic countries to start seriously tackling worms, specifically schistosomiasis and as a strategy to control STH in high endemic regions such as SSA [6], and WHO prepared PC guideline to control STH especially among $103 \mathrm{STH}$-endemic countries, and as this is often a worldwide rule, Part States are anticipated to adjust the proposal concurring to their setting and its achievability [20]. In line with this, integrated STH control strategies were designed in many countries in SSA, although the performance is not satisfactory related to limited funds to cascade the program [21].

For instance, a few funds have been committed by the Bill \& Melinda Gates Foundation (for backing), the USAID (up to $\$ 100$ million, with the probability of more in a long time to come), the Geneva Worldwide (\$8.9 million), and the British Government (up to $£ 50$ million promised for a few NTDs) for ten sub-Saharan African nations, namely Burkina Faso, Burundi, Ghana, Mali, Niger, Rwanda, Sierra Leone, Southern Sudan, Tanzania, and Uganda, to execute their national programs utilizing coordinates of neglected tropical diseases control. In any case, the funds accessible are not however adequate for these nations to scale up totally $[21,22]$.

To successfully control STH in STH-endemic countries, establishing an efficient STH control program in adolescent, pregnant, and lactating WRA is one of the six targets to be achieved by 2030 [23, 24]. STH control programs have been successful during the 2010-2020 decade, and a number of STH-endemic countries including most SSA countries conducted PC programs for more than 5 years, although few countries such as Botswana have not started the program [24].

As of 2017, the coverage of preventive chemotherapy was $<75 \%$ in Angola, Chad, Comoros, Democratic Republic of the Congo, Ethiopia, Gabon, and Kenya, whereas Congo, Côte d'Ivoire, Guinea, Liberia, Nigeria, Uganda, Zambia, and Zimbabwe implemented for less than 5 years and achieved $\geq 75 \%$. Similarly, Burundi, Cameroon, Ghana, Malawi, Rwanda, Sierra Leone, and Togo implemented for 5 years and more and achieved $\geq$ $75 \%$ preventive chemotherapy coverage. Few countries in SSA such as Benin, Burkina Faso, Mali, Niger, and Senegal recorded the moderate and heavy intensity less than $1 \%$ [24].

Specifically to pregnant women, WHO has set a target to achieve the coverage of deworming at $75 \%$ in 2030 [6, 24]. Available evidence shows that majority of pregnant women do not receive deworming medication [5]. For instance, a study in 49 STH endemic countries showed that about 688 million WRA living in STH endemic countries were in need of deworming medication as of 2015. However, about only $23 \%$ (95\% CI 19-28\%) of pregnant women received deworming medication during 
antenatal care (ANC) [5]. Another recent study in Cameroon shows only $29.8 \%$ of pregnant women received deworming medication during pregnancy [25].

Few studies on deworming medication are available in SSA. However, most of the available studies have focused on the estimation of coverage [5, 26], efficacy, safety, and tolerability of deworming medication [17]; effect of mass deworming [7] on schistosomiasis and all age of population [27], deceptive report [28], and on single health facility of a single country [26]. As a result, there is scarcity of evidence about both coverage and utilization of deworming medication and its associated factors among pregnant women in SSA. This study aimed at examining both the coverage and demographic, socio-economic, and women empowerment-related factors associated with the utilization of deworming medication among pregnant married women in 25 countries in SSA. The current study can help policy makers to evaluate the implementing policies and programs or design new policies regarding deworming medication utilization in the region.

\section{Methods}

\section{Study design}

This study was a cross-sectional study, and involved the extraction of data from the Demographic and Health Survey (DHS) of 26 countries in SSA conducted between 2010 and 2019. DHS is a nationally representative survey aimed to collect data on demographic and several health indicators including utilization of deworming medication across many LMICs [29]. DHS was carried out with financial aid from the United States Aid for International Development (USAID) and technical support of InnerCity Fund international [30]. During the DHS, a twostage stratified cluster sampling technique was applied [31]. In the first stage, enumeration areas (EAs) also called clusters were selected from sampling frame prepared from the recent population census. In the second stage, households (usually $25-30$ households) were selected from the clusters. We included 26 countries in SSA because of the inclusion criteria: availability of dependent variable and key explanatory variables and DHS conducted between 2010 and 2019. The analysis was done on 168,910 pregnant married women. The DHS datasets are freely available for download at https://dhsprogram.com/data/available-datasets.cfm. The reason we limited the analysis to married women was the inclusion of women empowerment variables which is applicable to married women as explanatory variables (women's decision-making power and wife beating attitude) [32, 33]. We followed the guidelines for Strengthening of Observational Studies in Epidemiology (STROBE) while preparing this manuscript [34]. Please refer to Table 1, for more details about studied countries and samples for the study.

\section{Study variables \\ Dependent variable}

The dependent variable of this study was utilization of deworming medication. The WHO recommends that a pregnant woman should take a single dose of mebendazole $(500 \mathrm{mg})$ or albendazole $(400 \mathrm{mg})$ after the first trimester [12, 25]. In DHS, women of reproductive age with birth history in the last 5 years preceding the survey are asked whether or not they took deworming medication, and the women responded as yes or no [13, 33]. Then, the dependent variable coded into binary as "yes" if the women took deworming medication and "no" if they did not take the deworming medication.

\section{Explanatory variables}

Based on available evidence on factors associated with uptake of deworming medication [5, 7, 17-19, 25-27], we included the following explanatory variables and categorized them primarily based on the DHS guide [26] and also used available studies on same topic. These included women's age $(15-19,20-24,25-29,30-34,35-$ 39, 40-44, 45-49), women's educational status (no formal education, primary school, secondary school, higher), husband's educational status (no formal education, primary school, secondary school, higher), women's occupation (not working, professional/technical/managerial, agricultural, manual, others), family size $(<5,5+)$, place of residence (urban, rural), religion (Christian, Muslim, others), timing of antenatal care (ANC) visits ( $\leq 3$ months, $>3$ months), number of ANC visit $(<4$ months, $\geq 4$ months), and wanted last birth (wanted then, wanted later, wanted no more). Other variables were wealth index, media exposure, decision-making power and attitude towards wife beating. In DHS, wealth index was computed using durable goods, household characteristics, and basic services following the methodology explained elsewhere [35], and was further categorized into five categories: poorest, poorer, middle, richer, and richest. Media exposure was coded as yes versus no. If the women read newspaper or listened to the radio or watched television for at least less than once a week, we coded as yes and coded as no otherwise.

In the DHS, married women aged 15-49 are asked three questions to measure their decision-making power within households: who decides about your own health? Who decides about large household purchases? Who decides on visit of families or relatives? The questions are intended to measure the women's decision-making power so as to indirectly examine whether or not the women are empowered or not. If the woman decided (either alone or together with her husband) on all the 
Table 1 Year of survey for each studied countries and sampled population

\begin{tabular}{|c|c|c|c|c|}
\hline \multirow[t]{2}{*}{ Country } & \multirow{2}{*}{$\begin{array}{l}\text { Year of } \\
\text { survey }\end{array}$} & \multicolumn{2}{|l|}{ Sampled population } & \multirow{2}{*}{$\begin{array}{l}\text { Coverage } \\
\text { of } \\
\text { deworming } \\
\text { medication }\end{array}$} \\
\hline & & Weighted number & Weighted percent & \\
\hline Angola & 2015/16 & 6361 & 3.77 & 2.03 \\
\hline Burkina Faso & 2010 & 9964 & 5.90 & 24.31 \\
\hline Benin & 2017/18 & 8331 & 4.93 & 64.39 \\
\hline Burundi & 2016/17 & 7621 & 4.51 & 67.60 \\
\hline Congo Democratic Republic & 2013/14 & 9551 & 5.65 & 55.64 \\
\hline Côte d'Ivoire & $2011 / 12$ & 4495 & 2.66 & 37.50 \\
\hline Cameroon & 2018/19 & 5013 & 2.97 & 29.82 \\
\hline Ethiopia & 2016 & 6662 & 3.94 & 5.73 \\
\hline Gabon & 2012 & 2875 & 1.70 & 71.58 \\
\hline Ghana & 2014 & 3631 & 2.15 & 39.71 \\
\hline Gambia & 2013 & 4974 & 2.94 & 40.82 \\
\hline Guinea & 2018 & 5138 & 3.04 & 38.07 \\
\hline Kenya & 2014 & 5904 & 3.50 & 31.81 \\
\hline Comoros & 2012 & 1878 & 1.11 & 63.16 \\
\hline Liberia & 2013 & 4035 & 2.39 & 58.56 \\
\hline Mali & 2018 & 6066 & 3.59 & 50.15 \\
\hline Malawi & $2016 / 17$ & 11,070 & 6.55 & 51.88 \\
\hline Nigeria & 2018 & 14,185 & 8.40 & 51.61 \\
\hline Rwanda & $2014 / 15$ & 4741 & 2.81 & 49.98 \\
\hline Sierra-Leone & 2019 & 6090 & 3.61 & 84.10 \\
\hline Senegal & 2010/11 & 7571 & 4.48 & 25.01 \\
\hline Chad & $2014 / 15$ & 10,248 & 6.07 & 23.31 \\
\hline Togo & $2013 / 14$ & 4556 & 2.70 & 57.16 \\
\hline Uganda & 2016 & 8429 & 5.00 & 60.50 \\
\hline Zambia & 2018/19 & 5496 & 3.25 & 77.76 \\
\hline Zimbabwe & 2015 & 4025 & 2.38 & 3.57 \\
\hline Total & & 168,910 & 100.00 & \\
\hline
\end{tabular}

three aforementioned decision-making parameters, the woman was considered to have decision-making power, and was coded as 1 , and otherwise considered as no decision-making power and coded as 0 [32, 33]. Similarly, in the DHS, women of reproductive age are asked five questions to measure wife beating attitude: do you agree with wife beating when a woman burns food? Do you agree with wife beating when a woman goes out without telling her husband? Do you agree with wife beating when a woman neglects children? Do you agree with wife beating when a woman argues with her husband? Do you agree with wife beating when a woman refuses to have sex with her husband? Then, if a woman responded that a husband was justified for wife beating for at least one of the five reasons, she was considered as justifying wife beating and we coded as 0 , and if the woman did not justify/disagreed for all of the five abovementioned wife beating reasons, she was considered as not justifying wife beating and was coded as 1 [32, 33, 36].

\section{Statistical analyses}

Using the Stata version 14.0 software, descriptive analysis such as frequency distribution was carried out to show the prevalence of deworming medication utilization. This was followed by Pearson chi-square test $\left(x^{2}\right)$ and multicollinearity test (using variance inflation factor $(\mathrm{VIF})$, mean $\mathrm{VIF}=1.84$, $\max \mathrm{VIF}=4.23$, min $\mathrm{VIF}=$ 1.06). Then, bivariate and multivariable logistic regression analysis followed by testing model fitness (using Hosmer-Lemeshow, $\mathrm{P}=0.3530$ ) was carried out. P-value less than 0.05 was used as a cutoff point for both 
Table 2 Frequency distribution of study participants and deworming distribution across explanatory variables: evidence from 26 sub-Saharan African countries DHSs

\begin{tabular}{|c|c|c|c|c|}
\hline \multirow[t]{2}{*}{ Variables } & \multirow{2}{*}{$\begin{array}{l}\text { Number } \\
\text { (weighted \%) }\end{array}$} & \multicolumn{2}{|c|}{ Deworming medication (weighted \%) } & \multirow{2}{*}{$\begin{array}{l}\text { Chi-square, } \\
\text { P-value }\end{array}$} \\
\hline & & No & Yes & \\
\hline Age in years & & & & $x^{2}=75.01, p<0.001$ \\
\hline $15-19$ & $17,193(7.86)$ & 62.99 & 37.01 & \\
\hline $20-24$ & $44,508(19.88)$ & 52.28 & 47.72 & \\
\hline $25-29$ & $55,243(21.60)$ & 44.80 & 55.20 & \\
\hline $30-34$ & $47,557(16.88)$ & 46.00 & 54.00 & \\
\hline $35-39$ & $40,591(14.56)$ & 47.03 & 52.97 & \\
\hline $40-44$ & $29,250(11.73)$ & 47.94 & 52.06 & \\
\hline $45-49$ & $22,617(7.51)$ & 63.62 & 36.38 & \\
\hline Women's educational status & & & & $x^{2}=615.81, p<0.001$ \\
\hline No formal education & $112,216(27.46)$ & 69.86 & 30.14 & \\
\hline Primary school & $80,241(38.90)$ & 50.82 & 49.18 & \\
\hline Secondary school & $54,423(29.65)$ & 30.77 & 69.23 & \\
\hline Higher & $10,069(3.98)$ & 22.70 & 77.30 & \\
\hline Husband's educational status & & & & $x^{2}=571.32, p<0.001$ \\
\hline No formal education & $96,580(21.13)$ & 66.22 & 33.78 & \\
\hline Primary school & $62,425(26.62)$ & 62.78 & 37.22 & \\
\hline Secondary school & $67,653(44.91)$ & 36.57 & 63.43 & \\
\hline Higher & $19,207(7.34)$ & 24.54 & 75.46 & \\
\hline Women's occupation & & & & $x^{2}=662.67, p<0.001$ \\
\hline Not working & $58,510(25.30)$ & 42.32 & 57.68 & \\
\hline Professional/technical/managerial & $9,517(5.41)$ & 33.64 & 66.36 & \\
\hline Agricultural & $79,991(29.67)$ & 73.21 & 26.79 & \\
\hline Manual & $16,683(3.39)$ & 40.35 & 59.65 & \\
\hline Others & $74,493(36.23)$ & 36.48 & 63.52 & \\
\hline Wealth index & & & & $x^{2}=1187.29, p<0.001$ \\
\hline Poorest & $58,177(17.92)$ & 80.63 & 19.37 & \\
\hline Poorer & $53,642(20.66)$ & 67.28 & 32.72 & \\
\hline Middle & $50,997(20.72)$ & 44.33 & 55.67 & \\
\hline Richer & 48,109 (20.59) & 29.96 & 70.04 & \\
\hline Richest & $46,034(20.11)$ & 21.83 & 78.17 & \\
\hline Media exposure & & & & $x^{2}=703.03, p<0.001$ \\
\hline No & $115,882(28.22)$ & 74.96 & 25.04 & \\
\hline Yes & 140,589 (71.78) & 38.51 & 61.49 & \\
\hline Family size & & & & $x^{2}=20.43, p<0.01$ \\
\hline$<5$ & 78,802 (33.09) & 53.6 & 46.40 & \\
\hline $5+$ & $178,157(66.91)$ & 47.41 & 52.59 & \\
\hline Religion & & & & $x^{2}=40.13, p<0.001$ \\
\hline Christian & $145,994(93.53)$ & 48.23 & 51.77 & \\
\hline Muslim & $100,493(0.36)$ & 46.09 & 53.91 & \\
\hline Others & $10,885(6.11)$ & 64.36 & 35.64 & \\
\hline ANC follow-up & & & & $x^{2}=1257.17, p<0.001$ \\
\hline No & 21,703 (18.33) & 96.17 & 3.83 & \\
\hline
\end{tabular}


Table 2 Frequency distribution of study participants and deworming distribution across explanatory variables: evidence from 26 sub-Saharan African countries DHSs (Continued)

\begin{tabular}{|c|c|c|c|c|}
\hline \multirow[t]{2}{*}{ Variables } & \multirow{2}{*}{$\begin{array}{l}\text { Number } \\
\text { (weighted \%) }\end{array}$} & \multicolumn{2}{|c|}{ Deworming medication (weighted \%) } & \multirow{2}{*}{$\begin{array}{l}\text { Chi-square, } \\
\text { P-value }\end{array}$} \\
\hline & & No & Yes & \\
\hline Yes & $159,944(81.67)$ & 38.73 & 61.27 & \\
\hline Timing of first ANC & & & & $x^{2}=60.41, p<0.001$ \\
\hline$>3$ months & $98,455(51.38)$ & 43.93 & 56.07 & \\
\hline$\leq 3$ months & $61,501(48.62)$ & 33.23 & 66.77 & \\
\hline Number of ANC visit & & & & $x^{2}=162.01, p<0.001$ \\
\hline$<4$ months & $68,864(24.89)$ & 53.94 & 46.06 & \\
\hline$\geq 4$ months & $91,080(75.11)$ & 33.69 & 66.31 & \\
\hline Wanted last birth & & & & $x^{2}=20.00, p<0.05$ \\
\hline Wanted then & $134,087(66.01)$ & 51.26 & 48.74 & \\
\hline Wanted later & $30,712(27.97)$ & 45.11 & 54.89 & \\
\hline Wanted no more & $10,340(6.02)$ & 46.67 & 53.33 & \\
\hline Decision making capacity & & & & $x^{2}=22.02, p<0.01$ \\
\hline No & $146,584(34.59)$ & 53.21 & 46.79 & \\
\hline Yes & $100,136(65.41)$ & 47.07 & 52.93 & \\
\hline Wife beating attitude & & & & $x^{2}=107.32, p<0.001$ \\
\hline Agreed for wife beating & $120,487(28.60)$ & 59.26 & 40.74 & \\
\hline Disagreed for wife beating & $126,324(71.40)$ & 45.04 & 54.96 & \\
\hline Barrier to healthcare services & & & & $x^{2}=82.83, p<0.001$ \\
\hline No & $83,661(30.50)$ & 40.57 & 59.43 & \\
\hline Yes & $154,366(69.50)$ & 53.01 & 46.99 & \\
\hline Place of residence & & & & $x^{2}=801.94, p<0.001$ \\
\hline Urban & $83,181(64.71)$ & 35.82 & 64.18 & \\
\hline Rural & $173,778(35.29)$ & 72.71 & 27.29 & \\
\hline
\end{tabular}

bivariate and multivariable logistic regression. To take care of the complex nature of the DHS's data, we used the "svyset" command during analysis, and all three design elements such as weight, cluster, and strata were taken into consideration.

\section{Ethical considerations}

We used publicly available secondary data for analysis of this study (available at https://dhsprogram.com/data/ available-datasets.cfm.). Ethical procedures were done by institutions that fund, commissioned, and managed the surveys, and no further ethical clearance was required. ICF international approved that all the DHS surveys follow the US Department of Health and Human Services rules, for respecting of human subject's rights. For more details related to ethical issues, readers can visit http:// goo.gl/ny8T6X.

\section{Results}

Sociodemographic characteristics of respondents

As shown in Table 2, a total of 168,910 participants were involved for analysis of this study. Of them, $7.9 \%$ of respondents were within 15-19 years while about $27.5 \%$ of respondents and $21.1 \%$ of their husbands did not attend formal education respectively. Approximately three quarters $(25.3 \%)$ of the respondents were not working, and $35.3 \%$ were rural residents. Meanwhile, $34.6 \%$ of married women had not decided for at least one reason of decision-making parameters: their own health, purchase large household expenses, and to visit families or relatives. About $28.6 \%$ of married women agreed or justified for wife beating for at least one of the five wife beating reasons.

\section{Utilization of deworming medication}

The pooled results show that more than half $(50.74 \%$, 95\% CI 48.15-53.31\%) of married women in the studied countries in SSA took deworming medications. As shown in Fig. 1, highest utilization coverage of deworming medication were seen in Sierra-Leone (84.1\%), Zambia (77.8\%), and Gabon (71.6\%) respectively, and lowest coverage was reported in Angola (2\%), Zimbabwe (3.6\%), and Ethiopia (5.7\%) respectively (Fig. 1). 


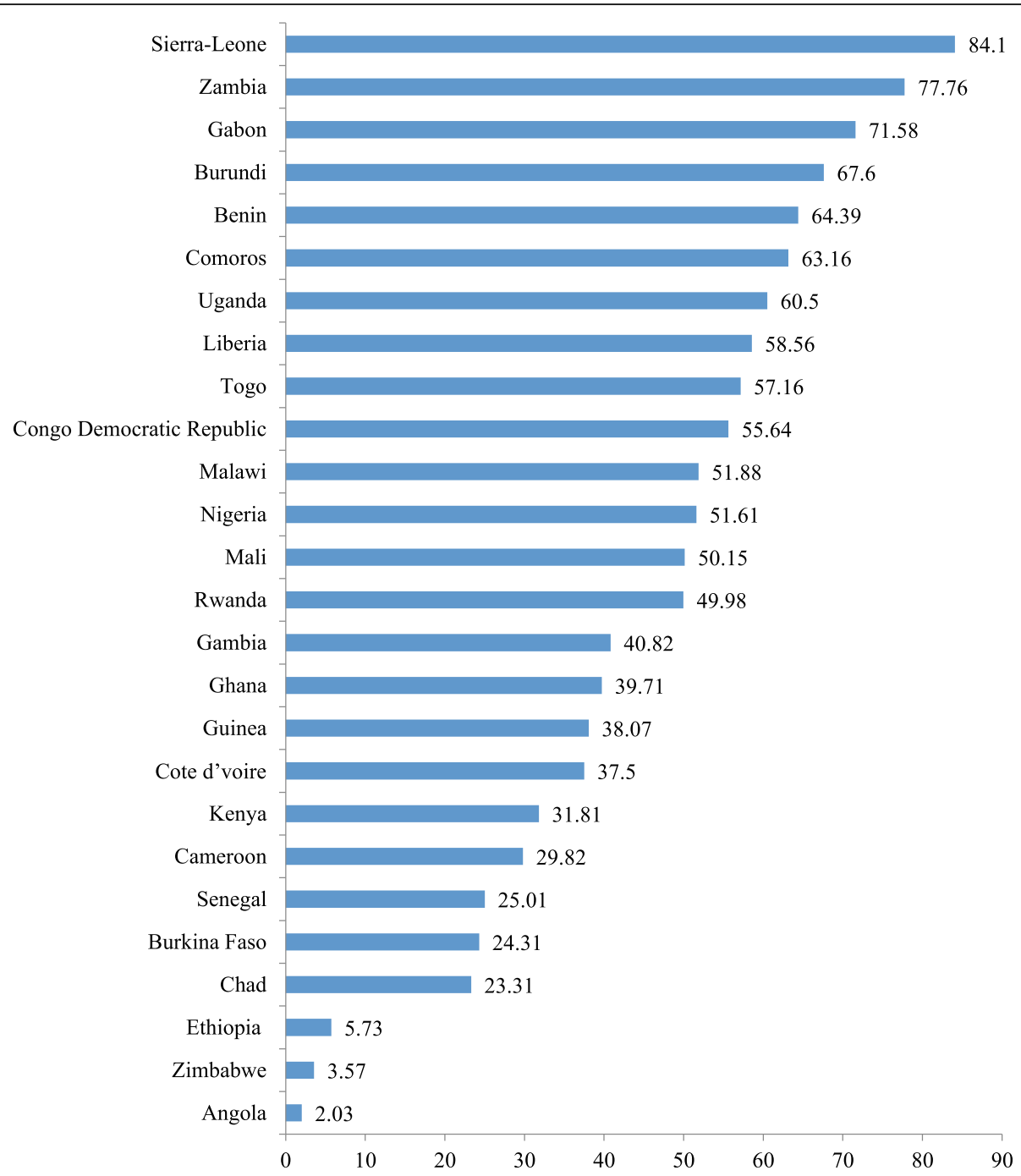

Fig. 1 Utilization coverage of deworming medication among married women: evidence from 25 SSA countries DHSs

As shown in Table 3, wide differences in utilization of deworming medication across sub-African regions are seen with highest coverage in East Africa (67.6\%, 95\% CI 66.0-69.1\%) region followed by Central Africa (50.7\%, 95\% CI 48.2-53.3\%) and lowest coverage in West Africa (24.3\%, 95\% CI 22.4-26.4\%) (Table 3).

\section{Utilization of deworming medication across explanatory variables}

Table 2 shows variations in utilization coverage of deworming medication across explanatory variables and subcategories. For instance, utilization of deworming medication varied from 30.1 to $77.3 \%$ between married women who had not attended formal education and those who had attended higher education, respectively (Fig. 2).
Similarly, among married women between poorest and richest subpopulation, utilization of deworming medication varied from 19.4 to $78.2 \%$, respectively (Fig. 3).

About $61.5 \%$ of married women who had media exposure were taking deworming medication, while not more than of $25 \%$ of married women who had no media exposure took deworming medication. Moreover, about $61.5 \%$ of married who were exposed to media, could it be newspaper, radio, or television, took deworming medication, but the coverage lowered to $25 \%$ among married women with no media exposure. Utilization of deworming medication also varied from 46.1 to $66.3 \%$ between married women with less than four ANC visits and four and above ANC visits respectively (Table 2 ). 
Table 3 Coverage of utilization of deworming medication among pregnant married women by sub-regions: evidence from 26 subSaharan African countries DHSs

\begin{tabular}{|c|c|c|}
\hline Sub-regions & Included countries & Pooled sub-regional coverage \\
\hline \multirow[t]{12}{*}{ West Africa } & Burkina Faso & $24.3 \%$ (95\% Cl 22.4-26.4\%) \\
\hline & Benin & \\
\hline & Côte d'Ivoire & \\
\hline & Ghana & \\
\hline & Gambia & \\
\hline & Guinea & \\
\hline & Liberia & \\
\hline & Mali & \\
\hline & Nigeria & \\
\hline & Sierra-Leone & \\
\hline & Senegal & \\
\hline & Togo & \\
\hline \multirow[t]{5}{*}{ Central Africa } & Angola & $50.7 \%$ (95\% Cl 48.2-53.3\%) \\
\hline & Congo Democratic Republic & \\
\hline & Cameroon & \\
\hline & Gabon & \\
\hline & Chad & \\
\hline \multirow[t]{9}{*}{ East Africa } & Burundi & $67.6 \%$ (95\% Cl 66.0-69.1\%) \\
\hline & Ethiopia & \\
\hline & Kenya & \\
\hline & Comoros & \\
\hline & Malawi & \\
\hline & Rwanda & \\
\hline & Uganda & \\
\hline & Zambia & \\
\hline & Zimbabwe & \\
\hline
\end{tabular}

\section{Factors associated with utilization of deworming} medication

Table 4 shows bivariate and multivariable logistic regression analysis of factors associated with utilization of deworming medication. The bivariate analysis shows that women's age, women's educational status, husband's educational status, women's occupation, wealth index, media exposure, family size, place of residence, barriers to healthcare services, religion, timing of ANC visit, number of ANC visit, wanted last birth, wife beating attitude, and decision making were associated with utilization of deworming medication. However, the multivariable analysis shows that women's age, husband's educational status, wealth index, media exposure, and number of ANC visit were factors associated with utilization of deworming medication.

More specifically, we found higher odds of utilization of deworming medication among married women within the age groups of $25-29$ years $(\mathrm{aOR}=1.57$, 95\% CI $1.13-$
2.18), 30-34 years $(\mathrm{aOR}=1.58,95 \% \mathrm{CI} 1.10-2.28), 35-39$ years $(\mathrm{aOR}=1.93,95 \% \mathrm{CI} 1.32-2.84)$, and 40-44 years (aOR $=1.92$, 95\% CI 1.25-2.95) compared to married women within 15-19 years of age. The study shows higher odds of utilization of deworming medication among married women whose husband attended secondary school $(\mathrm{aOR}=1.40,95 \%$ CI $1.11-1.77)$ compared to married women whose husband did not attend formal education.

Moreover, higher odds of utilization of deworming medication were observed among married women in the middle $(\mathrm{aOR}=1.77,95 \% \mathrm{CI} 1.24-2.51)$, richer $(\mathrm{aOR}=2.39$, 95\% CI 1.55-3.69), and richest (3.12, 95\% CI 1.95-4.99) households compared to married women in the poorest households. We found higher odds of utilization of deworming medication among married women who had media exposure $(\mathrm{aOR}=1.46,95 \% \mathrm{CI} 1.18-1.80)$ compared to married women who had no media exposure. Finally, in this study, there were higher odds of 


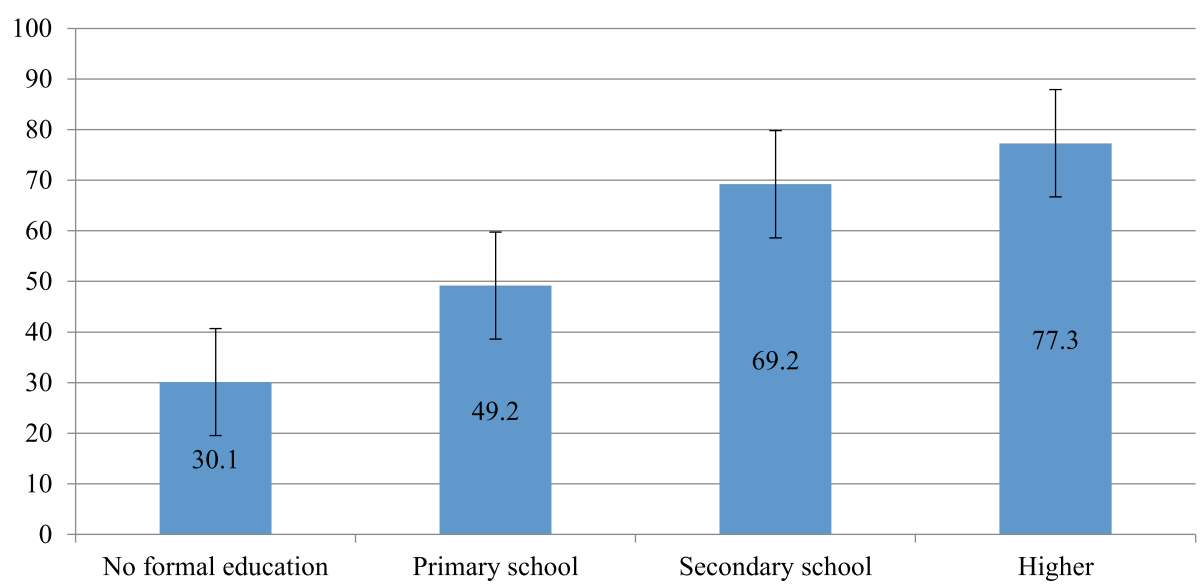

Fig. 2 Utilization of deworming medication among pregnant women based on educational level: evidence from 26 sub-Saharan African countries DHSs

utilization of deworming medication among married women who had four and above ANC visits $(\mathrm{aOR}=1.51$, 95\% CI 1.24-1.83) compared to married women who had less than four ANC visits (Table 4).

\section{Discussion}

In this study, using nationally representative data, we investigated the coverage and sociodemographic, socioeconomic, and women empowerment-related factors associated with deworming medication utilization among pregnant married women in 26 sub-Saharan African countries. The pooled result shows that more than half $(50.74 \%)$ of married women in the studied countries took deworming medications. The finding from this study was higher compared to the study conducted among $49 \mathrm{STH}$ endemic countries that showed 23\% of pregnant women received deworming medication [5]. The variations in the coverage of utilization of deworming medication between these two studies might partly relate to variation in methodology of the studies (married women versus all reproductive age women, and study area/included countries). In this study, utilization coverage of deworming medication varied from as high as $84.1 \%$ in Sierra-Leone to as low as $2 \%$ in Angola. Concerning sub-African region variations, highest and lowest coverage of utilization of deworming medication among pregnant married women was seen in East Africa (67.6\%) and West Africa (24.3\%) regions respectively. The variations across African regions and countries might be related to factors associated with utilization of deworming medication such as socioeconomic factors [16-18] and time effect (the year when the DHS data was collected across countries; 2010 to 2019).

Women's age was associated with utilization of deworming medication. More specifically, we found higher odds of utilization of deworming medication among older married women compared to adolescent married women. The plausible reason could be higher educational and career accomplishment as well as better family income which increase with age [37, 38]. Older women usually are proactive, and they emphasize on prevention of diseases $[37,39]$, which could be related to their previous experience [37].

The study showed higher odds of utilization of deworming medication among married women whose husbands were educated, compared to married women whose husbands did not have formal education. Women with educated husbands have better uptake of maternal health services due to the fact that educated husbands participate in promoting their wives' health and have positive relationship with their wives [40]. In addition, educated husbands are more likely to encourage their wives to seek and utilize healthcare services during pregnancy [41]. On the other hand, husbands with no formal education may prevent their wives from utilizing health services due to being uncomfortable with touching or examining their wives [42]. The other reason about husband's education effect is its linkage with income and wealth [43]. Scholars have documented that education is the noticeable factor to get employment opportunities, earn better, and increase individual, communities, and national economic growth [44-46] that again has positive influence in accessing healthcare services [47, 48]. Hence, to use the positive impact of husband education, increasing national education coverage, husbandoriented health education programs, and involvement of husband in maternal healthcare services may be the policy recommendations $[49,50]$.

Moreover, the study showed higher odds of utilization of deworming medication among married women from higher socio-economic households compared to married women in the poorest households. This finding is 


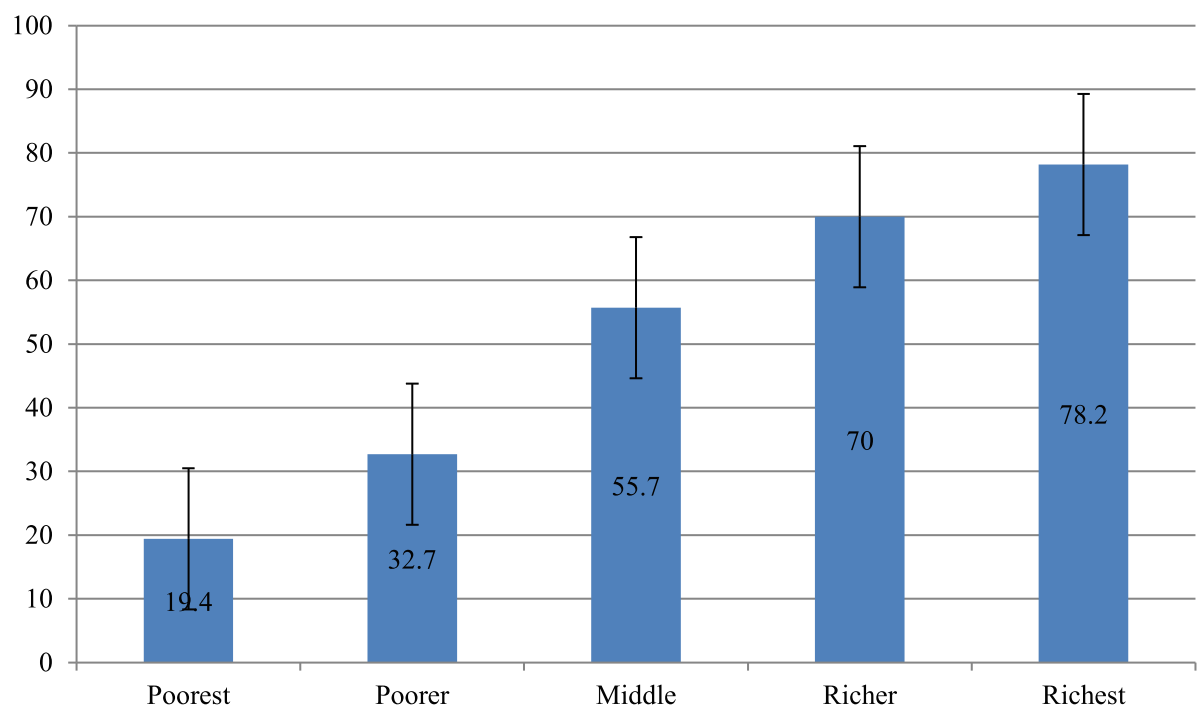

Fig. 3 Utilization of deworming medication among pregnant women based on household economic status: evidence from 26 sub-Saharan African countries DHSs

comparable with a prior study in Ghana [51]. Compared to wealthier women, economically disadvantaged women encounter problems in accessing healthcare services due to direct costs such as payment for medication that may include the possibility of paying for medication in the time when stock runs out from the dispensary and indirect costs such as transport costs and unpaid working hours [40, 47, 48, 52]. Unfortunately, the burden of helminthic infection and its consequences, anemia, is more prevalent among individual or communities within countries of low socioeconomic status such as South East Asia and Africa [53-55]. Therefore, giving attention to women in economically disadvantaged households could be one intervention mechanism for enhancement of uptake of deworming medication.

Pregnant women need correct information about healthcare services, and it can help them to have information about the available healthcare services and their needs through visual appealing, audio message, and printed reports $[42,56]$. In this study, we found higher odds of utilization of deworming medication among married women who were exposed to media, compared to married women who had no media exposure. Prior studies in India [57], Bangladesh [58], South Asia [42], Uganda [59], and Malawi [60] documented the influence of media on maternal health services. Mass media could have tremendous role in the dissemination of health-related information and development of knowledge for mothers especially for those population groups with less education and those who live in rural setting [42, 57]. Therefore, media- focused regional and national public health policies and practices including prepare campaign and ongoing health education programs using mass media need to be considered to increase the uptake of deworming medication [61].

We found higher odds of utilization of deworming medication among married women who had four and above ANC visits compared to married women who had less than four ANC visits. ANC visit is a good opportunity to receive deworming medication because more information about benefits of deworming and positive pregnancy outcomes are gained through counseling during repeated ANC visits [13]. Therefore, governments should reduce or eliminate barriers that limit number of ANC visits such as long distance to health facilities that may be aggravated by difficult geographical/road conditions [62], and strengthening the use of ANC services in the region as newly recommended by WHO is expected from the health sector and needs to become an agent to coordinate and work with other sectors so as to enhance uptake of deworming medication among pregnant women.

In this study, women's decision-making power and wife beating attitude was not associated with uptake of deworming medication. This might indirectly tell us access to and utilization of maternal healthcare services among married women are strongly determined by husband educational level [63]. Moreover, gender inequity such as husband's financial status within the household might determine the uptake of maternal health services [64]. In fact, getting permission from husband is one of the four 
Table 4 Bivariate and multivariable logistic regression output for factors associated with utilization of deworming medication among married women: evidence from 26 SSA countries DHSS

\begin{tabular}{|c|c|c|c|c|}
\hline Variables & Model I cOR [95\% Cl) & P-value & Model II aOR [95\% CI) & P-value \\
\hline \multicolumn{5}{|l|}{ Age in years } \\
\hline $15-19$ & Ref & & Ref & \\
\hline $20-24$ & $1.55(1.17-2.05)$ & 0.002 & $1.27(0.91-1.78)$ & 0.147 \\
\hline $25-29$ & $2.09(1.59-2.74)$ & $\mathrm{p}<0.001$ & $1.57(1.13-2.18)$ & 0.007 \\
\hline $30-34$ & $1.99(1.48-2.67)$ & $\mathrm{p}<0.001$ & $1.58(1.10-2.28)$ & 0.013 \\
\hline $35-39$ & $1.91(1.42-2.57)$ & $\mathrm{p}<0.001$ & $1.93(1.32-2.84)$ & 0.001 \\
\hline $40-44$ & $1.84(1.26-2.70)$ & 0.002 & $1.92(1.25-2.95)$ & 0.003 \\
\hline $45-49$ & $0.97(0.59-1.60)$ & 0.914 & $1.15(0.63-2.11)$ & 0.630 \\
\hline \multicolumn{5}{|l|}{ Women's educational status } \\
\hline No formal education & Ref & & Ref & \\
\hline Primary school & $2.24(1.84-2.73)$ & $\mathrm{p}<0.001$ & $1.03(0.81-1.30)$ & 0.791 \\
\hline Secondary school & $5.21(4.15-6.54)$ & $\mathrm{p}<0.001$ & $1.04(0.77-1.39)$ & 0.786 \\
\hline Higher & $7.89(4.73-13.16)$ & $\mathrm{p}<0.001$ & $1.00(0.53-1.88)$ & 0.992 \\
\hline \multicolumn{5}{|l|}{ Husband's educational status } \\
\hline No formal education & Ref & & Ref & \\
\hline Primary school & $1.16(0.91-1.47)$ & 0.214 & $1.10(0.86-1.40)$ & 0.435 \\
\hline Secondary school & $3.40(2.76-4.17)$ & $\mathrm{p}<0.001$ & $1.40(1.11-1.77)$ & 0.004 \\
\hline Higher & $6.02(4.13-8.79)$ & $\mathrm{p}<0.001$ & $1.28(0.86-1.91)$ & 0.214 \\
\hline \multicolumn{5}{|l|}{ Women's occupation } \\
\hline Not working & Ref & & Ref & \\
\hline Professional/technical/managerial & $1.44(0.94-2.20)$ & 0.085 & $0.86(0.53-1.40)$ & 0.554 \\
\hline Agricultural & $0.26(0.21-0.33)$ & $\mathrm{p}<0.001$ & $0.85(0.67-1.07)$ & 0.181 \\
\hline Manual & $1.08(0.72-1.62)$ & 0.695 & $0.86(0.54-1.36)$ & 0.521 \\
\hline Others & $1.27(1.03-1.57)$ & 0.024 & $0.99(0.78-1.25)$ & 0.978 \\
\hline \multicolumn{5}{|l|}{ Wealth index } \\
\hline Poorest & Ref & & Ref & \\
\hline Poorer & $2.02(1.54-2.65)$ & $\mathrm{p}<0.001$ & $1.32(0.97-1.80)$ & 0.071 \\
\hline Middle & $5.22(3.87-7.04)$ & $\mathrm{p}<0.001$ & $1.77(1.24-2.51)$ & 0.001 \\
\hline Richer & $9.73(7.11-13.31)$ & $p<0.001$ & $2.39(1.55-3.69)$ & $p<0.001$ \\
\hline Richest & $14.90(10.40-21.35)$ & $\mathrm{p}<0.001$ & $3.12(1.95-4.99)$ & $p<0.001$ \\
\hline \multicolumn{5}{|l|}{ Media exposure } \\
\hline No & Ref & & Ref & \\
\hline Yes & $4.77(3.96-5.76)$ & $\mathrm{p}<0.001$ & $1.46(1.18-1.80)$ & $p<0.001$ \\
\hline \multicolumn{5}{|l|}{ Family size } \\
\hline$<5$ & Ref & & Ref & \\
\hline $5+$ & $1.28(1.09-1.49)$ & 0.002 & $1.13(0.93-1.39)$ & 0.197 \\
\hline \multicolumn{5}{|l|}{ Place of residence } \\
\hline Urban & Ref & & Ref & \\
\hline Rural & $0.20(0.16-0.26)$ & $\mathrm{p}<0.001$ & $0.98(0.74-1.30)$ & 0.935 \\
\hline \multicolumn{5}{|l|}{ Barriers to healthcare services } \\
\hline No & Ref & & Ref & \\
\hline Yes & $0.60(0.50-0.72)$ & $\mathrm{p}<0.001$ & $0.87(0.72-1.07)$ & 0.200 \\
\hline
\end{tabular}

Religion 
Table 4 Bivariate and multivariable logistic regression output for factors associated with utilization of deworming medication among married women: evidence from 26 SSA countries DHSs (Continued)

\begin{tabular}{|c|c|c|c|c|}
\hline Variables & Model I cOR [95\% Cl) & P-value & Model II aOR [95\% Cl) & P-value \\
\hline Christian & Ref & & Ref & \\
\hline Muslim & $1.08(0.29-3.98)$ & 0.897 & $1.73(0.23-12.94)$ & 0.592 \\
\hline Others & $0.51(0.35-0.74)$ & $p<0.001$ & $1.04(0.71-1.51)$ & 0.824 \\
\hline \multicolumn{5}{|l|}{ ANC follow-up } \\
\hline No & Ref & & - & - \\
\hline Yes & 39.74 (26.60-59.37) & $\mathrm{p}<0.001$ & - & - \\
\hline \multicolumn{5}{|l|}{ Timing of ANC visit } \\
\hline$>3$ months & Ref & & Ref & \\
\hline$\leq 3$ months & $1.57(1.32-1.86)$ & $\mathrm{p}<0.001$ & $1.09(0.91-1.31)$ & 0.303 \\
\hline \multicolumn{5}{|l|}{ Number of ANC visit } \\
\hline$<4$ month & Ref & & Ref & \\
\hline$\geq 4$ month & $2.30(1.92-2.76)$ & $\mathrm{p}<0.001$ & $1.51(1.24-1.83)$ & $p<0.001$ \\
\hline \multicolumn{5}{|l|}{ Wanted last birth } \\
\hline Wanted then & Ref & & Ref & \\
\hline Wanted later & $1.27(1.08-1.51)$ & 0.004 & $1.01(0.83-1.22)$ & 0.901 \\
\hline Wanted no more & $1.20(0.87-1.64)$ & 0.249 & $1.06(0.75-1.48)$ & 0.731 \\
\hline \multicolumn{5}{|l|}{ Wife beating attitude } \\
\hline Agreed for wife beating & Ref & & Ref & \\
\hline Disagreed for wife beating & $1.77(1.49-2.11)$ & $\mathrm{p}<0.001$ & $1.19(0.99-1.43)$ & 0.056 \\
\hline \multicolumn{5}{|l|}{ Decision-making capacity } \\
\hline No & Ref & & Ref & \\
\hline Yes & $1.27(1.07-1.52)$ & 0.007 & $1.10(0.90-1.35)$ & 0.340 \\
\hline
\end{tabular}

Notes: Ref reference

Hyphen (-) indicates not included variable at model II due to small proportion of subgroups

main barriers to access healthcare services [47, 48]. Several prior studies also documented the strong association between husband education and/or involvement with uptake of maternal health service utilization [65-67]. Therefore, considering designing policies that target on enhancing husband education coverage and involvements help to increase the uptake of maternal health services including deworming medication $[64,67]$.

\section{Strengths and limitations of the study}

Determining utilization coverage of deworming medication and investigating its demographic, socioeconomic, and women empowerment-related factors among pregnant married women using nationally representative, large sample size and across several countries (25 countries in SSA) is the main strength of this study. The findings of this study could be used by policy makers to improve the uptake of deworming medication in SSA. In terms of limitations, although we attempted to incorporate many countries, due to the inclusion criteria, we only included few countries in SSA, and the findings may not be generalizable to all sub-Saharan African countries. Moreover, since we were interested in examining women empowerment-related factors, which are applicable to married women only, we could not include non-married women, and therefore, findings are limited to married women. Third, the cross-sectional nature of the study could not allow for inferring causaleffect relationship. Lastly, the time when the surveys were conducted varied by up to 9 years across studied countries and that needs to be considered as it may affect the comparisons due to the time effect.

\section{Conclusion}

The pooled results show that about half of married women received deworming medication during their pregnancy. Women's age, husband's educational status, wealth index, media exposure, and number of ANC visits were factors associated with utilization of deworming medication. Therefore, enhancing women's education, involving men in women's health programs, accessing women's use of media especially 
those who are not literate and living in rural areas and disseminating information about maternal healthcare services through mass media, and ensuring that economically disadvantaged households benefit from national economic growth can be considered as policy measures. Moreover, providing more attention to adolescent or young pregnant women and strengthening ANC services including increasing number of ANC visits can be another solution for increased uptake of deworming medication among married pregnant women especially in West African countries.

\section{Abbreviations}

Cl: Confidence intervals; DHS: Demographic and Health Surveys; STH: Soiltransmitted helminthiasis; WHO: World Health Organization

\section{Acknowledgements}

The authors thank the MEASURE DHS project for their support and for free access to the original data.

\section{Declarations}

\section{Authors' contributions}

SY and BZ contributed to the study design and conceptualization. BZ reviewed the literature and performed the analysis. MK, BOA, EKA, AS, and SY provided technical support and critically reviewed the manuscript for its intellectual content. SY had final responsibility to submit for publication. The authors read and amended drafts of the paper and approved the final version.

\section{Funding}

There was no funding for this study.

\section{Availability of data and materials}

Data for this study were sourced from the Demographic and Health surveys (DHS) and available here: http://dhsprogram.com/data/available-datasets.cfm.

\section{Ethics approval and consent to participate}

Ethics approval was not required for this study since the data is secondary and is available in the public domain. More details regarding DHS data and ethical standards are available at http://goo.gl/ny8T6X.

\section{Consent for publication}

No consent to publish was needed for this study as we did not use any details, images, or videos related to individual participants. In addition, data used are available in the public domain.

\section{Competing interests}

The authors declare that they have no competing interests.

\section{Author details}

${ }^{1}$ HaSET Maternal and Child Health Research Program, Shewarobit Field Office, Shewarobit, Ethiopia. ${ }^{2}$ Department of Population Studies, Faculty of Social Sciences, University of Botswana, Private Bag, UB 0022 Gaborone, Botswana. ${ }^{3}$ School of Public Health, Faculty of Health, University of Technology Sydney, Sydney, NSW 2007, Australia. ${ }^{4}$ Department of Population and Health, University of Cape Coast, Cape Coast PMB 0494, Ghana. ${ }^{5}$ College of Public Health, Medical and Veterinary Sciences, James Cook University, Townsville, QLD 4811, Australia. ${ }^{6}$ School of International Development and Global Studies, Faculty of Social Sciences, University of Ottawa, 120 University Private, Ottawa, ON K1N 6N5, Canada. ${ }^{7}$ The George Institute for Global Health, Imperial College London, London, UK.
Received: 27 April 2021 Accepted: 9 June 2021

Published online: 30 June 2021

\section{References}

1. World Health Organization. (2013b). Soil-transmitted helminth infectionsfact sheet No. 366, Available at: http://www.sciepub.com/reference/328233. Accessed on 07 Apr 2021

2. Pullan RL, Smith JL, Jasrasaria R, Brooker SJ. Global numbers of infections and disease burden of soil transmitted helminth infections in 2010. Parasit Vectors. 2014;7(1):37.

3. Mupfasoni D. Estimation of the number of women of reproductive age in need of preventive chemotherapy for soil-transmitted helminth (STH) infections. PLoS Negl Trop Dis. 2018;12(2):e0006269.

4. Report of the WHO Advisory Group on deworming in girls and women of reproductive age. Rockefeller Foundation Bellagio Center, Bellagio, Italy. 2830 June 2017 (WHO/ CDS/NTD/PCT/2018.01). Geneva: World Health Organization; 2018. Licence: CC BY-NC-SA 3.0 IGO.

5. Bangert M, Bancalari P, Mupfasoni D, Mikhailov A, Gabrielli AF, Montresor A. Provision of deworming intervention to pregnant women by antenatal services in countries endemic for soil-transmitted helminthiasis. PLoS Negl Trop Dis. 2019;13(5):e0007406.

6. WHO. Soil-transmitted helminth infections, 2020. Available at: https://www who.int/news-room/fact-sheets/detail/soil-transmitted-helminth-infections. Accessed on 07 Apr 2021.

7. Salam RA, Cousens S, Welch V, Gaffey M, et al. Mass deworming for soiltransmitted helminthes and schistosomiasis among pregnant women: a systematic review and individual participant data meta-analysis. Campbell Syst Rev. 2019;15(3):e1052.

8. Ahenkorah B, Nsiah K, Baffoe P, Ofosu W, Gyasi C, Owiredu E-W. Parasitic infections among pregnant women at first antenatal care visit in northern Ghana: a study of prevalence and associated factors. PLOS ONE. 2020;15(7): e0236514.

9. Paranjpe S, Roopa N, Avani K, Gita N, Preeti M. Prevalence of intestinal parasites in pregnant women. Indian J Microbiol Res. 2020;7(4):350-7.

10. World Bank. Prevalence of anemia among reproductive age (\% of women ages 15-49). Available at: https://data.worldbank.org/indicator/SH.ANM.A LLW.ZS. Accessed on 07, Apr 2021

11. World Bank. Prevalence of anemia among pregnant women (\%) - SubSaharan Africa | Data. Available at: https://data.worldbank.org/indicator/SH PRG.ANEM?locations=ZG. Accessed on May 22, 2021

12. WHO. e-Library of Evidence for Nutrition Actions (eLENA) Deworming in pregnant women, 2019. Available from: https://www.who.int/elena/titles/ deworming_pregnancy/en/. Accessed on 07, Apr 2020

13. WHO. WHO recommendations on antenatal care for a positive pregnancy experience. Geneva: World Health Organization; 2016.

14. Larocque R, Gyorkos TW. Should deworming be included in antenatal packages in hookworm-endemic areas of developing countries? Can J Public Health. 2006;97(3):222-4.

15. Christian P, Khatry SK, West KP. Antenatal anthelmintic treatment, birth weight, and infant survival in rural Nepal. Lancet. 2004;364(9438):981-3.

16. Atukorala TM, de Silva LD, Dechering WH, Dassenaeike TS, Perera RS. Evaluation of effectiveness of iron-folate supplementation and anthelminthic therapy against anemia in pregnancy - a study in the plantation sector of Sri Lanka. Am J Clin Nutr. 1994:60(2):286-92.

17. Lau R, Chris RB, Phuong MS, Khatib A, Kopalakrishnan S, Bhasker S, et al. Treatment of soil-transmitted helminth infections in pregnancy: a systematic review and meta-analysis of maternal outcomes. J Travel Med. 2020;27(2): taz079.

18. Walia B, Kmush BL, Lane SD, Endy T, Montresor A, Larson DA. Routine deworming during antenatal care decreases risk of neonatal mortality and low birth weight: a retrospective cohort of survey data. MedRxiv (PREPRINT). 2020

19. de Silva NR, Sirisena JL, Gunasekera DP, Ismaill MM, de Silva HJ. Effect of mebendazole therapy during pregnancy on birth outcome. Lancet. 1999; 353(9159):1145-9.

20. Guideline: preventive chemotherapy to control soil-transmitted helminth infections in at-risk population groups. Geneva: World Health Organization; 2017. Licence: CC BY-NC-SA 3.0 IGO. 
21. Fenwick A, Zhang Y, Stoever K. Control of the neglected tropical diseases in sub-Saharan Africa: the unmet needs. Int Health. 2009;1(1):61-70. https://doi. org/10.1016/j.inhe.2009.06.002.

22. Hotez PJ, Molyneux DH, Fenwick A, Savioli L, Takeuchi T. A global fund to fight neglected tropical diseases: is the G8 Hokkaido Toyako 2008 Summit ready? PLoS Negl Trop Dis. 2008;2(3pg):e220.

23. Vegvari C, Giardina F, Bajaj S, Malizia V, Hardwick RJ, Truscott JE, et al. Deworming women of reproductive age during adolescence and pregnancy: what is the impact on morbidity from soil-transmitted helminths infection? Parasit Vectors. 2021;14:220. https://doi.org/10.1186/s13 071-021-04620-w.

24. WHO. Neglected tropical diseases. 2030 targets for soil-transmitted helminthiases control programmes. Geneva: World Health Organization; 2019. License: CC BY-NC-SA 3.0IGO

25. Zegeye B, Ahinkorah BO, Ameyaw EK, Seidu A-A, Yaya S. Utilization of deworming drugs and its individual and community level predictors among pregnant married women in Cameroon: a multilevel modeling. Biomed Res Int. 2021;6645336:12. https://doi.org/10.1155/2021/6645336.

26. Shiferaw MB, Zegey AM, Mengistu AD. Helminth infections and practice of prevention and control measures among pregnant women attending antenatal care at Anbesame health center, Northwest Ethiopia. BMC Res Notes. 2017;10:274

27. Torres-Vitolas CA, Dhanani N, Fleming FM. Factors affecting the uptake of preventive chemotherapy treatment for schistosomiasis in Sub-Saharan Africa: a systematic review. PLoS Negl Trop Dis. 2021;15(1):e0009017.

28. Gyorkos TW, Montresor A, Belizario V, Biggs B-A, Bradley M, Brooker SJ, et al. The right to deworming: the case for girls and women of reproductive age. PLoS Negl Trop Dis. 2018;12(11):e0006740.

29. DHS Program. Methodology: survey type. Available at: https://dhsprogram. com/methodology/survey-Types/dHs.cfm. Accessed on 27 March 2021.

30. The DHS Program- quality information to plan, monitor and improve population, health, and nutrition programs. Available at: https://dhsprogram. com/. Accessed on 27 March 2021

31. DHS Program. Guide to DHS statistics. Analyzing DHS data. Available at: https://dhsprogram.com/data/Guide-to-DHS-Statistics/Analyzing_DHS_Data. htm. Accessed on 12 March 2021

32. Kishor S, Subaiya L. Understanding women's empowerment: a comparative analysis of Demographic and Health Surveys (DHS) data. DHS Comparative Reports No. 20. Calverton, Maryland, USA: Macro International Inc.; 2008. Available at: https://dhsprogram.com/publications/publication-cr20-compara tivereports.cfm. Accessed on May 29, 2021

33. Trevor NC, Marshall AMJ, Allen CK. Guide to DHS statistics. Rockville: ICF; 2018. Available at: https://dhsprogram.com/data/Guide-to-DHS-Statistics/ index.cfm. Accessed on May 29, 2021

34. von Elm E, Altman DG, Egger M, Pocock SJ, Gøtzsche PC, Vandenbroucke $J P$. The strengthening the reporting of observational studies in epidemiology (STROBE) statement: guidelines for reporting observational studies. Int J Surg. 2014;12(12):1495-9.

35. Rutsein SO, Johnson K. The DHS wealth index. DHS Comparative Reports No. 6. Calverton: ORC Macro; 2004.

36. Yaya S, Zegeye B, Ahinkorah BO, Seidu A-A, Ameyaw EK, Adjei NK, et al. Predictors of skilled birth attendance among married women in Cameroon: further analysis of 2018 Cameroon Demographic and Health Survey. Reprod Health. 2021;18:70. https://doi.org/10.1186/s12978-021-01124-9.

37. Kato T, Yorifuji T, Yamakawa M, Inoue S, Doi H, Eboshida A, et al. Association of maternal age with child health: a Japanese longitudinal study. PLoS ONE. 2017;12(2):e0172544. https://doi.org/10.1371/journal.pone.0172544.

38. Benzies K, Tough S, Tofflemire K, Frick C, Faber A, Newburn-Cook C. Factors influencing women's decisions about timing of motherhood. J Obstet Gynecol Neonatal Nurs. 2006;35(5):625-33.

39. Nelson AM. A qualitative study of older first-time mothering in the first year. J Pediatr Health Care. 2004;18(6):284-91. https://doi.org/10.1016/S0891524 504000896.

40. Shibre G, Zegeye B, Idriss-Wheeler D, Sanni YS. Factors affecting the utilization of antenatal care services among women in Guinea: a population-based study. Fam Pract. 2020:1-7.

41. Adjiwanou V, Bougma M, LeGrand T. The effect of partners' education on women's reproductive and maternal health in developing countries. Soc Sci Med. 2018;197:104-15.

42. Fatemaa K, Lariscy JT. Mass media exposure and maternal healthcare utilization in South Asia. SSM-Population Health. 2020;11:100614.
43. Wolla SA, Sullivan J. Education, income, and wealth: PAGE ONE Economics; 2017. Available online: https://research.stlouisfed.org/publica tions/page1-econ/2017/01/03/education-income-wealth/. Accessed on 5 April 2021

44. Grant C. The contribution of education to economic growth. Knowledge, Evidence and Learning for Development; Helpdesk Report. Brighton: Institute of Development Studies; 2017.

45. Hanushek EA, Woessmann L. Do better schools lead to more growth? Cognitive skills, economic outcomes, and causation. J Econ Growth. 2012;17 267-321.

46. Cloete N. Higher education and economic development in Africa. In: Vucasovic M, Maassen P, Nerland M, Stensaker B, Pinheiro R, Vabo A, editors. Effects of higher education reforms. Higher Education Research in the 21st Century Series. Rotterdam: Sense Publishers; 2012. p. 4.

47. WHO. In: World Health Organization, editor. Barriers and facilitating factors in access to health services in Greece barriers and facilitating factors in access to health services in Greece. Copenhagen; 2015.

48. Zegeye B, El-Khatib Z, Ameyaw EK, Seidu A-A, Ahinkorah BO, Keetile M, et al. Breaking barriers to healthcare access: a multilevel analysis of individualand community-level factors affecting women's access to healthcare services in Benin. Int J Environ Res Public Health. 2021;18:750. https://doi. org/10.3390/ijerph18020750.

49. Teklesilasie W, Deressa W. Barriers to husbands' involvement in maternal health care in Sidama zone, Southern Ethiopia: a qualitative study. BMC Pregnancy Childbirth. 2020;20:21.

50. Mullany BC, Becker S, Hindin MJ. The impact of including husbands in antenatal health education services on maternal health practices in urban Nepal: results from a randomized controlled trial. Health Educ Res. 2007; 22(2):166-76.

51. Lumor O, Dzabeng F, Adanu RM. Factors influencing the use of anemia preventing measures among antenatal clinic attendees in the Kintampo North Municipality, Ghana. Afr J Reprod Health. 2019;23(2):35.

52. Zegeye B, Ahinkorah BO, Idriss-Wheelr D, Oladimeji O, Olorunsaiye CZ, Yaya S. Predictors of institutional delivery service utilization among women of reproductive age in Senegal: a population-based study. Arch Public Health. 2021;79:5. https://doi.org/10.1186/s13690-020-00520-0.

53. WHO. Preventive chemotherapy in human helminthiasis: coordinated use of antihelminthic drugs in control interventions: a manual for health professionals and programme managers. Geneva: World Health Organization; 2006. Available from: http://apps.who.int/iris/bitstream/1 0665/43545/1/9241547103_eng.pdf. Accessed on 07, Apr 2020

54. WHO. The global prevalence of anaemia in 2011. Geneva: World Health Organization; 2015. Available from: http://apps.who.int/iris/bitstream/1 0665/177094/1/9789241564960_eng.pdf. Accessed on 07 Apr 2020

55. WHO. State of inequality: reproductive, maternal, newborn and child health. Geneva: World Health Organization; 2015. Available from: http://www.who. int/gho/health_equity/report_2015/en/. Accessed on 07 Apr, 2020

56. Galea S. Mass media. Macro social determinants of population health. New York, NY: Springer; 2007. p. 275-94.

57. Ghosh D. Effect of mothers' exposure to electronic mass media on knowledge and use of prenatal care services: a comparative analysis of Indian states. Prof Geogr. 2006;58(3):278-93.

58. Uddin MF. Impact of mass media on antenatal care (ANC) utilization in Bangladesh (Vol. 149): Institute for Population and Social Research (IPSR), Mahidol University; 2009.

59. Asp G, Pettersson KO, Sandberg J, Kabakyenga J, Agardh A. Associations between mass media exposure and birth preparedness among women in southwestern Uganda: a community-based survey. Glob Health Action. 2014;7(1):22904.

60. Zamawe CO, Banda M, Dube AN. The impact of a community driven mass media campaign on the utilization of maternal healthcare services in rural Malawi. BMC Pregnancy Childbirth. 2016;16(1):21.

61. Gollust SE, Fowler EF, Niederdeppe J. Television news coverage of public health issues and implications for public health policy and practice. Annu Rev Public Health. 2019;40(1):167-85.

62. Gupta S, Yamada G, Mpembeni R, Frumence G, Callaghan-Koru JA, Stevenson $\mathrm{R}$, et al. Factors associated with four or more antenatal care visits and its decline among pregnant women in Tanzania between 1999 and 2010. PLoS ONE. 2014;9(7):e101893.

63. Tarekegn SM, Lieberman LS, Giedraitis V. Determinants of maternal health service utilization in Ethiopia: analysis of the 2011 Ethiopian 
Demographic and Health Survey. BMC Pregnancy Childbirth. ns2014;14:161.

64. Yaya S, Okonofua F, Ntoimo L, Udenige O, Bishwajit G. Gender inequity as a barrier to women's access to skilled pregnancy care in rural Nigeria: a qualitative study. Int Health. 2019;11(6):551-60.

65. Singh A, Ram F. Men's involvement during pregnancy and childbirth: evidence from Rural Ahmadnagar, India. Popul Rev. 2009;48:83-102.

66. Tsegaye B, Shudura E, Yoseph A, Tamiso A. Predictors of skilled maternal health services utilizations: a case of rural women in Ethiopia. PLoS ONE. 2021;16(2):e0246237.

67. Lewis S, Lee A, Simkhada P. The role of husbands in maternal health and safe childbirth in rural Nepal: a qualitative study. BMC Pregnancy Childbirth. 2015;15:162

\section{Publisher's Note}

Springer Nature remains neutral with regard to jurisdictional claims in published maps and institutional affiliations.

Ready to submit your research? Choose BMC and benefit from:

- fast, convenient online submission

- thorough peer review by experienced researchers in your field

- rapid publication on acceptance

- support for research data, including large and complex data types

- gold Open Access which fosters wider collaboration and increased citations

- maximum visibility for your research: over $100 \mathrm{M}$ website views per year

At BMC, research is always in progress.

Learn more biomedcentral.com/submissions 